Boardwalk or eating in a restaurant I would run into Eugene Braunwald, Kurt Isselbacher, Donald Seldin, Lloyd (Holly) Smith, or James Wyngaarden, among others, and they would stop for a brief moment and congratulate me on a paper I had presented that day. It is part of the fuel that drives us, to be accepted by the people you greatly admire. It was this experience that convinced me in subsequent years and up to this day to greet, shake hands with, and spend a minute or two speaking with the young aspiring physician-scientists who I run into at the spring meetings, be they in Washington, DC, Baltimore, the West Coast, or, as has been the case for the past several years, Chicago.

\section{Membership in ASCI}

There are few thrills in the life of a young physician-scientist more exciting than election to membership in the ASCI. I had attended several successive ASCI meetings following my introduction to the ritual in 1969. I had published a few articles in The Journal of Clinical Investigation. I was still a little starstruck, but now I wanted not only to be accepted by the people who I admired, but to actually be one of them. In the early spring of 1976, after toiling for four years as a young independent investigator, I was elected to membership in the ASCI. I was ecstatic. Yet in an interesting twist, membership in the Society, as opposed to being an end in itself, actually became for me an incentive to perform at an even higher level in order to live up to the tradition established by the many distinguished members who had preceded me. In speaking with several of my peers, they expressed similar reactions to their ASCI elections. We were elected into the club on the basis of merit. Now that we were part of the club, we needed to continue to perform like we belonged there. Although membership in the ASCI is often a requirement for further academic advancement including promotions and resources, I maintain that the internal bar that it sets for us is as important as anything else.

\section{The future of the ASCI}

I believe that the future of the ASCI will be healthy and enduring. The fundamental principles upon which clinical research is based are inherent to the principles of the ASCI: excellence in science, creativity, integrity, and service to the public through clinical research to improve the health of the nation and the world. The future of clinical research can only remain healthy if we continue to train outstanding young men and women who will push the envelope of science and continue to explore the unknown. These individuals will benefit from associating with a tradition of excellence and productivity. I am certain that the ASCI will continue to provide this milieu for them and will serve as an important goal for those young people who aspire to emulate their idols and mentors just as I did when I took that first drive from Bethesda to Atlantic City in the spring of 1969.

Address correspondence to: Anthony S. Fauci, NIAID, NIH, Building 31, Room 7A-03, 9000 Rockville Pike, 31 Center Drive MSC 2520, Bethesda, Maryland, USA. Phone: (301) 496-2263; Fax: (301) 496-4409; E-mail: afauci@niaid.nih.gov.

1. Fauci, A.S., and Dale, D.C. 1974. The effect of in vivo hydrocortisone on subpopulations of human lymphocytes. J. Clin. Invest. 53:240-246.

2. Hixson, J.R. 1976. The patchwork mouse. Anchor Press. New York, New York, USA. 228 pp.

3. Relman, A.S. 1969. Academic medicine and the public. J. Clin. Invest. 48:1169-1171.

4. Zerhouni, E. 2006. NIH in the post-doubling era: realities and strategies. Science. 314:1088-1090.

\title{
ASCl: reflections on the first 100 years and a proposal for the next
}

\author{
William N. Kelley
}

University of Pennsylvania, Philadelphia, Pennsylvania, USA.

\begin{abstract}
ASCI
Congratulations to the ASCI and its membership on the first 100 years. From their first organizational meeting on the Boardwalk in Atlantic City in June 1907, our predecessors recognized the need for an organization for the clinician who had a strong interest in true experimental medicine. These nine Young Turks formed the Society, had their first meeting at the Willard Hotel in Washington, DC, in
went on to become some of the leaders of American medicine in the first half of the 20th century. The 100тн 1909, and went on to become some of the leaders of American medicine in the first half of the 20th century. The
establishment of the JCI in 1924 further enhanced the high standards of the ASCI and its membership. Surely thousands of us have benefited from the foundation of the ASCI and the JCI, as have, I would submit, millions of patients as well.
\end{abstract}

\section{Reflections}

My first serious exposure to research began in the summer of 1965 when I arrived at the NIH as a clinical associate in the National Institute of Arthritis and Metabolic Diseases. I had done some research as a medical student at Emory University, first in a cardiovascular laboratory in the Pharmacology Department under Marion Cotton and later in the General Clinical

Conflict of interest: The author has declared that no conflict of interest exists. Citation for this article: J. Clin. Invest. 118:1217-1219 (2008). doi:10.1172/JCI34652.
Research Center under Garland Herndon. As wonderful as those experiences were, I knew I was in a different league as I walked into Building 10, known then as the Clinical Center, on the NIH campus on July 1, 1965. This massive building is a large hospital encircled by research laboratories sitting in the middle of a large campus, around which there are dozens of other research and administrative buildings. In addition, once inside, I was struck by the pristine, well-attended, and quiet patient care units on each floor surrounded by multiple wings of research space. This was also not the wild and woolly West that I had experienced 
in my two years as a resident in internal medicine at Parkland Hospital in Dallas.

At the entry to each laboratory, the lab director's name was on a faceplate. Here, again, I was pleasantly surprised to see one after another of the famous names in science and medicine. These were people who had written so much of the literature from which I had been learning over the past six years of my life. These were the characters so widely quoted by my colleagues on the wards in the middle of the night. These were the stars about whom the faculty at UT Southwestern had spoken so well over the past two years. I had truly reached nirvana.

What followed was the beginning of a professional experience that was the best one could ask for. I was working with Jay Seegmiller, one of my research rock stars based on his work in gout, a favorite disease of mine. I truly experienced the excitement of doing science and learning from the best in the world. This was capped off by the joy of discovery as our experiments, both basic and at the bedside, unraveled the mysteries of the Lesch-Nyhan syndrome (1) and what was later to be called Kelley-Seegmiller syndrome (2). The latter was made more famous, at least for my family, in an episode of the television program House on May 15, 2007 , than by the patients with it or the physicians diagnosing and treating them.

\section{Clinical meetings}

The first meeting I attended of the Tri-Societies (ASCI, AAP, and AFMR) or the "clinical meetings," as they were known then, was in spring 1966 in Atlantic City. I was truly impressed with the great names in medicine who seemed to be everywhere, the vast crowds (with an occasional friend here and there) hustling up and down the Boardwalk, the rigor of the scientific presentations followed by intense and insightful questions from those in attendance, and the large auditorium in the Haddon Hall hotel filled with thousands of highly attentive physician-scientists of all ages who were focused on the plenary presentations of original unpublished research. The vibrancy of the whole event was truly memorable. I can remember returning to the lab in Bethesda after that first meeting full of excitement with ideas for what we might be able to apply to our own research.

In 1968, after completing two years as a clinical associate at the NIH and a year as a senior resident in Medicine at Massachusetts General Hospital, I joined the faculty at Duke. With this transition, I became involved with the usual extramural academic expectations, such as study sections, editorial boards, visiting professorships, etc. By 1971, at the age of 31, I was elected to membership in the ASCI, and in 1975 I was elected to membership in the AAP. I began to know more and more people involved in the research and who attended the meetings, and I became more involved with the issues of concern to the three societies. As I recall, the large crowds continued, and the excitement was as stimulating as ever. We were presenting more work from our lab and going through all of the usual rehearsals and preparations to be ready for any possible question or comment. However, as the years passed, things began to change. By the mid-1970s it was clear that Atlantic City was changing. It was becoming increasingly seedy and run down, and it appeared that legalized gambling was inevitable. I recall as a member of the AFMR Council our discussions that we would need to move. We had our last TriSocieties meeting in Atlantic City in 1976 and moved to Washington, DC, for our 1977 national meeting.
The move to Washington made a lot of sense for the two senior societies and especially for the ASCI. The first meeting of the ASCI in 1909 had been in Washington, and so, for many, this was a return to our origins. For the first few years in DC, things went pretty well. I was very much involved in the planning of the Tri-Societies meeting over the next few years, since I served as president of the AFMR in 1979-1980 and as president of the ASCI in 1983-1984 (3). We missed the Boardwalk, which had its own special meaning to many of us. We were always concerned about growth in attendance at the meetings and with providing what was desired by our membership. We had new competitors because of the substantial expansion of medical and pediatric specialty societies, which were becoming more attractive venues for presenting one's research. I viewed this as a healthy challenge for us and a stimulus to try new things to continuously improve. By now, the giants leading the programs were my colleagues and friends. Upon completion of my term as president of the ASCI over 20 years ago, I basically left the internecine politics of these meetings. I had plenty else to keep me busy.

In 1989, we moved from Ann Arbor, Michigan, where I had been chair of the Department of Internal Medicine since 1975, and I assumed my new position as dean of the School of Medicine of the University of Pennsylvania and CEO of its Medical Center (and later Health System), and I felt it was necessary to give up my laboratory pursuits. Hence, by the beginning of the ' 90 s, I became an attendee out of interest in hearing about the science and seeing friends, but only a very distant observer in terms of the meeting itself.

Some time in the mid-1990s, the Tri-Societies decided to part ways. The AFMR went its own way, and the ASCI and AAP continued to meet together. These two honorific societies now meet regularly in Chicago in April. I find this meeting very useful. The opportunity to hear presentations covering, in effect, a review of key fields of science by the leaders in those fields is perfect for me. Special topics, award lectures, the presidential addresses, and, of course, the Kober Medal presentation are terrific. The leaders are now the next generation, heavily represented, I am proud to say, by many of my once junior colleagues and mentorees. However, I dearly miss the cast of thousands of junior scientists of which I was once a member only 40 years ago.

\section{ASCI membership}

One of the most important functions for the ASCI is the election of new members who represent the crème de la crème of the young clinical investigators. I surely recall with great pride my election to membership; one joined the ranks of a very special group of young scientists. As I recall from those days, there were only 40 elected each year, and all had to be 45 or younger. From a group of superachievers who had a history of a series of successes, this very special additional recognition afforded by election to the ASCI represented an important achievement for the physician-scientist, which clearly set him or her apart from the rest. In addition to the benefit to the individual, it provided a level of peer recognition appreciated by promotion committees, by outside leaders searching for highly qualified candidates for positions as division chiefs, directors of centers and institutes, and department chairs, and, indeed, it appears to serve as one criterion for election to the AAP.

\section{The Journal of Clinical Investigation}

I have had the opportunity to work with, and to be benefited by, the JCI over the years. This included service as a member of the editorial 
board from 1974 to 1979 and more recently the opportunity to serve as senior editor, a tour that began with the move of the editorial offices to Philadelphia this past spring. Over the years, I was pleased to have been able to publish over 20 papers from my lab in the JCI.

The benefit of having such a highly regarded journal in the field of clinical investigation cannot be overstated. It serves to define the field. It sets a standard by which all others are measured. Through decisions that are made at the level of the editorial board, it ensures that ethical and rational behavior is demanded of those wishing to publish their work there.

Because of its prestige, the JCI also brings great credibility to the institution where the journal locates its editorial offices. I recall well my recurring efforts to have my institution selected as the venue for the journal. This started while I was on the faculty at Duke from 1968 to 1975. I recall an effort to bring the journal to Durham, but we lost out to UT Southwestern and later to Washington University, both extremely strong institutions. I recall a similar effort during my later years at the University of Michigan, where we likewise failed. In 1997, we made a strong bid from the University of Pennsylvania. We lost to the University of Michigan. Knowing the tremendous strengths of the faculty at the University of Michigan, whom I knew well, I did take vicarious pleasure in their selection (especially if Penn had to lose on that try). So you can imagine my pleasure when the University of Pennsylvania was selected this last go-around as the location of the editorial offices. This was made even more pleasurable since I had virtually nothing to do with the massive effort that had to be made to be successful in the selection process.

\section{Looking to the future}

Despite the many positives of our current annual meetings, they are seriously marred by a black hole among our attendees - our junior colleagues are missing. We will have lost an important battle on behalf of science and medicine if we can't bring to our annual meeting substantial numbers of those physician-scientists who are to be the leaders of the future. As much as I enjoy the current meetings, which are ideal for me and perhaps many others of my generation, the loss of contact with the students, trainees, and junior faculty is a serious deficiency. More importantly, as I look back on my early years as a clinical investigator, I believe our junior colleagues of today have lost, unknowingly, far more than we have. I know that many of us are concerned about this loss. Our current meetings seem to have a stable attendance in the range of 400 or so each year. The AFMR averages about 400 attendees per meeting as well, even though this number also includes other societies such as the Association for Patient-Oriented Research. Obviously, this is a major change for both groups from the several thousand attending the Tri-Societies meetings in the '70s. This analysis also suggests that reestablishing a joint meeting of the Tri-Societies is unlikely, in and of itself, to fully achieve our goal. In addition, I am aware of efforts to involve in the annual meeting many from the various $\mathrm{MD} / \mathrm{PhD}$ programs, both students and program directors. This, too, is important, since clearly this is a stellar group. Can we do more?

I would like to propose to the leadership of the ASCI, and optimally the AAP as well, an additional approach for enhancing the relationship between our membership and the potential stars of clinical research in future generations. One of the key features of both the ASCI and the AAP is that election to membership in these organizations is honorific. I believe we should consider forming an honorific society for the young physician-scientist. Perhaps this society would be to the outstanding young clinical investigator what Alpha Omega Alpha is to the medical student. One would want to devise a mechanism that would include medical students, postdoctoral physician trainees, and young faculty as potential nominees. Perhaps associated with this honor would be one or more all-expenses-paid trips to participate and present at our annual meeting and, of course, a focused effort to make this meeting highly productive for them. While one would expect this new society to be independent and self-perpetuating eventually, perhaps some oversight from its more senior colleagues would be useful in the early years. The senior societies might also wish to involve a segment of their membership to help develop plans for this new society. An example of an untapped but highly accomplished group that could be helpful is the previous Kober Medal awardees.

\section{Conclusion}

The ASCI has served an important role in its first 100 years. Our challenge for the next 100 years will be to continue this legacy of providing the leadership to support the physician-scientist in his or her pursuit of basic, clinical, translational, and health services research contributing to the improved health of the human race. This is no small task at this point in time, given the many issues faced by those of us in this field. The obstacles are immense and mutifactorial, and no small set of solutions will suffice. Among the many moves that will be necessary, I conclude that the time has come for the ASCI and the AAP to form a new honorific society for the rising stars. I encourage the leadership of the ASCI and its sister society to make this a major focus of their efforts in the near future.

Address correspondence to: William N. Kelley, Department of Medicine, University of Pennsylvania School of Medicine, Suite 757 - BRB II/III, 421 Curie Boulevard, Philadelphia, Pennsylvania 19104-6160, USA. Phone: (215) 573-9953; Fax: (772) 365-0514; E-mail: kelleyw@mail.med.upenn.edu.

1. Seegmiller, J.E., Rosenbloom, F.M., and Kelley, W.N. 1967. Enzyme defect associated with a sex-linked human neurological disorder and excessive purine synthesis. Science. 155:1682-1684.

2. Kelley, W.N., Greene, M.L., Rosenbloom, F.M., Henderson, J.F., and Seegmiller, J.E. 1969. Hypoxanthine-guanine phosphoribosyltransferase deficiency in gout. Ann. Intern. Med. 70:155-206.

3. Kelley, W.N. 1984. Clinical investigation and the clinical investigator: the past, present, and future. J. Clin. Invest. 74:1117-1122. 